
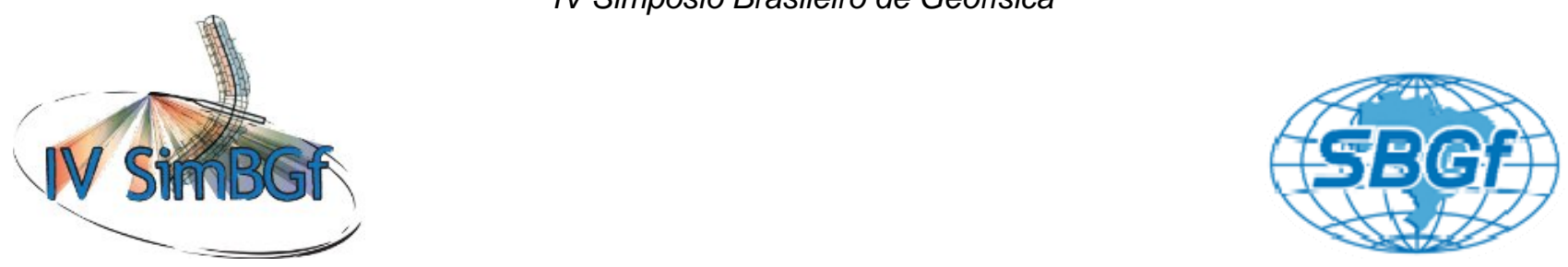

\title{
Dados gamaespectrométricos e magnetométricos aéreos aplicados à exploração de ouro em Fazenda Nova, porção leste do Arco Magmático de Arenópolis, Goiás
}

Lara Nigro Ramos, Augusto César Bittencourt Pires, Universidade de Brasília - UnB/ LGA

Copyright 2010, SBGf - Sociedade Brasileira de Geofísica

Este texto foi preparado para a apresentação no IV Simpósio Brasileiro de Geofísica Brasília, 14 a 17 de novembro de 2010. Seu conteúdo foi revisado pelo Comitê Técnico do IV SimBGf, mas não necessariamente representa a opinião da SBGf ou de seus associados. É proibida a reprodução total ou parcial deste material para propósitos comerciais sem prévia autorização da SBGf.

\section{Resumo}

Este estudo utilizou imagens derivadas do processamento de dados magnetométricos e gamaespectrométricos como suporte à prospecção de ouro em Fazenda Nova, localizada na porção centrooeste do Estado de Goiás, por intermédio da identificação de zonas de alteração hidrotermal, as quais possuem relação com a mineralização aurífera. Estas zonas foram reveladas a partir do reconhecimento de áreas enriquecidas em potássio mediante as imagens geradas pelas técnicas Potássio Anômalo e Fator-F, além da razão K/Th. Foram selecionados alvos prospectivos nas imagens dos três critérios adotados para a identificação da presença de áreas com conteúdo anômalo em potássio.

\section{Introdução}

O Arco Magmático de Goiás é inserido no chamado Cinturão de $\mathrm{Au}-\mathrm{Cu}$ de Arenópolis-Mara Rosa que hospeda inúmeros depósitos de ouro e cobre-ouro (Oliveira, 2000), desenvolvidos nos diversos estágios da evolução da FDB. Estes depósitos e ocorrências de ouro corroboram para a importância metalogenética deste ambiente geotectônico em programas de exploração mineral (Kuyumjian \& Jost, 2009). No Arco Magmático de Arenópolis são conhecidos os depósitos Bom Jardim de Goiás (Cu-Au) e Bacilândia (Au), além de diversas ocorrências de ouro, as quais constituem garimpos desativados e depósitos conhecidos. Na porção leste deste arco localiza-se a área de estudo, a qual hospeda diversas ocorrências minerais auríferas e a Mina de Bacilândia, mina de ouro desativada, lavrada entre os anos 2004 e 2008. Avaliação petrográfica de testemunhos de sondagem desta mina indicou associação da mineralização com zonas de alteração hidrotermal, caracterizadas por sericitização, carbonatação e sulfetação. Zonas hidrotermalizadas associadas ao enriquecimento de minerais potássicos são possíveis de serem detectadas mediante técnicas aplicadas nos dados de radiometria gama e observação dos lineamentos e estruturas geológicas ilustradas pela magnetometria.

Dados aerogeofísicos constituem importante ferramenta na procura por depósitos minerais e na interpretação de feições geológicas. Zonas mineralizadas podem ser indicadas em aerolevantamentos a partir da detecção de minerais-minérios que difiram em uma ou mais propriedades físicas e/ou químicas enquanto que as variações observadas em dados magnéticos e gamaespectrométricos são usualmente utilizadas na delimitação de estruturas e na discriminação de unidades geológicas, respectivamente.

Neste contexto, os trabalhos desenvolvidos nesta pesquisa envolveram o processamento e interpretação de dados gamaespectrométricos e magnetométricos aéreos como auxílio à prospecção de ouro na região de Fazenda Nova, localizada na porção centro-oeste do Estado de Goiás (Fig. 1).

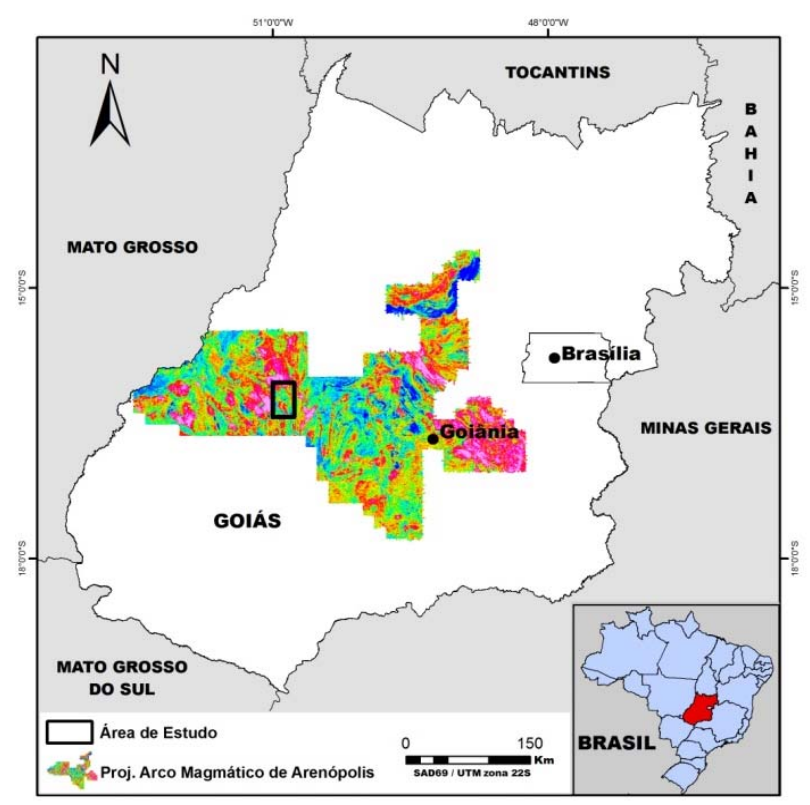

Figura 1 - Localização da área de estudo e do aerolevantamento intitulado Projeto Arco Magmático de Arenópolis.

O Arco Magmático de Arenópolis constitui um arco de ilha com acreção ocorrida entre 900 e $600 \mathrm{Ma}$, caracterizado por metaplutônicas expostas entre seqüências metavulcano-sedimentares, justapostas ao longo de falhas NNW e NNE (Pimentel \& Fuck, 1992). Na área de estudo afloram litotipos relacionados ao arco, como ortognaisses de composição granítica à granodiorítica, metavulcânicas máficas e félsicas da Seqüência Vulcano-Sedimentar de Jaupaci e granitos pós-orogênicos, além de litotipos jovens, representados 
por corpos cretáceos da Província Alcalina de Goiás e sedimentos paleozóicos da Bacia do Paraná (Fig. 2).

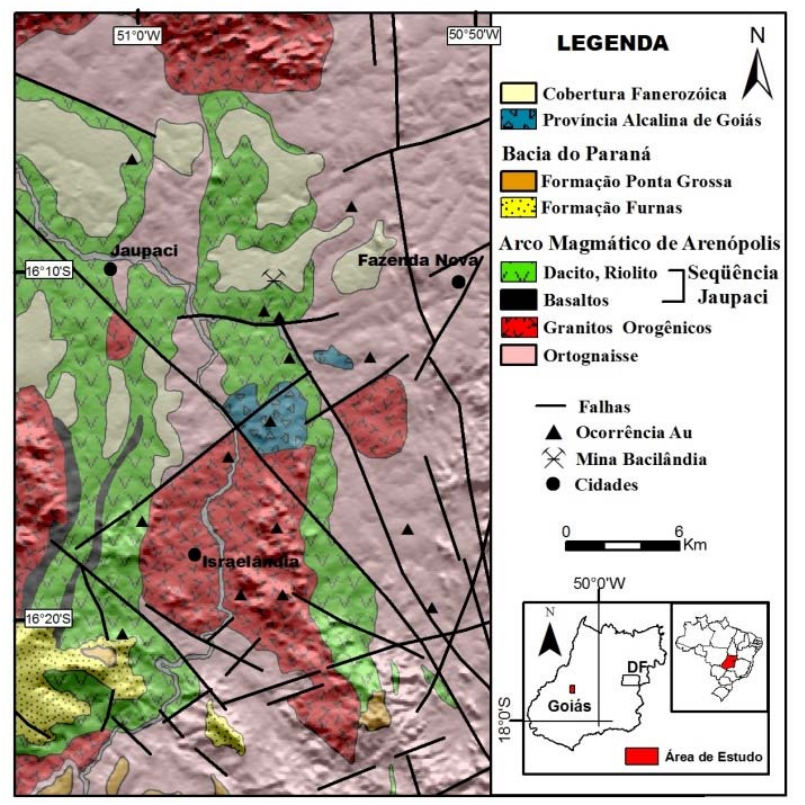

Figura 2 - Mapa geológico da área de estudo sobreposto à imagem SRTM (Shuttle Radar Topography Mission).

\section{Metodologia}

Os dados aerogeofísicos são provenientes do aerolevantamento referente ao Projeto Arco Magmático de Arenópolis realizado em 2004 (Fig. 1). O projeto recobriu uma área de $58.834 \mathrm{~km}^{2}$ e objetivou a coleta de dados gamaespectrométricos e magnetométricos ao longo de perfis com orientação N-S e espaçamento de $0,5 \mathrm{~km}$. As linhas de controle foram espaçadas por $5,0 \mathrm{~km}$ e são perpendiculares às linhas de vôo (E-W).

Neste estudo foram realizadas as correções, o processamento, a interpolação e o micro-nivelamento dos dados magnéticos e de espectrometria de raios gama para a confecção das imagens aerogeofísicas, de acordo com o fluxograma da Fig. 3. Os dados gamaespectrométricos foram interpolados em malha regular (grids) por intermédio do método curvatura mínima, enquanto que para os dados magnetométricos foi utilizado o interpolador bi-direcional. O tamanho da célula unitária utilizada na confecção dos grids foi 100m, que representa $1 / 5$ do espaçamento das linhas de vôo, o que está de acordo com Vasconcelos et al. (1994) e Gunn (1998). O micro-nivelamento foi realizado com o algoritmo MicroLevel.gs desenvolvido por Blum (1999) e baseado na técnica de Minty (1991).

Após o micro-nivelamento dos dados, foram geradas imagens magnetométricas e gamaespectrométricas com emprego de técnicas de sombreamento e composição em falsa cor em RGB e CMY. Para os dados de espectrometria de raios gama, o processamento consistiu na geração de imagens dos canais $\mathrm{K}, \mathrm{U}$, Th e Contagem Total, razões entre os canais e imagens ternárias. As técnicas Potássio Anômalo (Pires, 1995) e Fator F
(Efimov, 1978 In Gnojek \& Prichystal, 1985) foram aplicadas com o intuito de realçar áreas enriquecidas em potássio, possíveis de constituírem zonas de alteração hidrotermais relacionadas à mineralização aurífera. Essas técnicas relacionam os radioelementos $\mathrm{K}$ e Th para indicar áreas anômalas em potássio, já que estes elementos apresentam comportamento antagônico (Ostrovsky, 1975). O processamento e realce do campo magnético anômalo geraram as imagens das derivadas vertical e horizontais, da inclinação do sinal analítico e da amplitude do gradiente horizontal, as quais forneceram informações sobre o arcabouço estrutural da área. As interpretações qualitativas das imagens aerogeofísicas foram feitas em ambiente de Sistema de Informação Geográfica (SIG) com o programa ArcView ${ }^{\mathrm{TM}}$ 9.2.

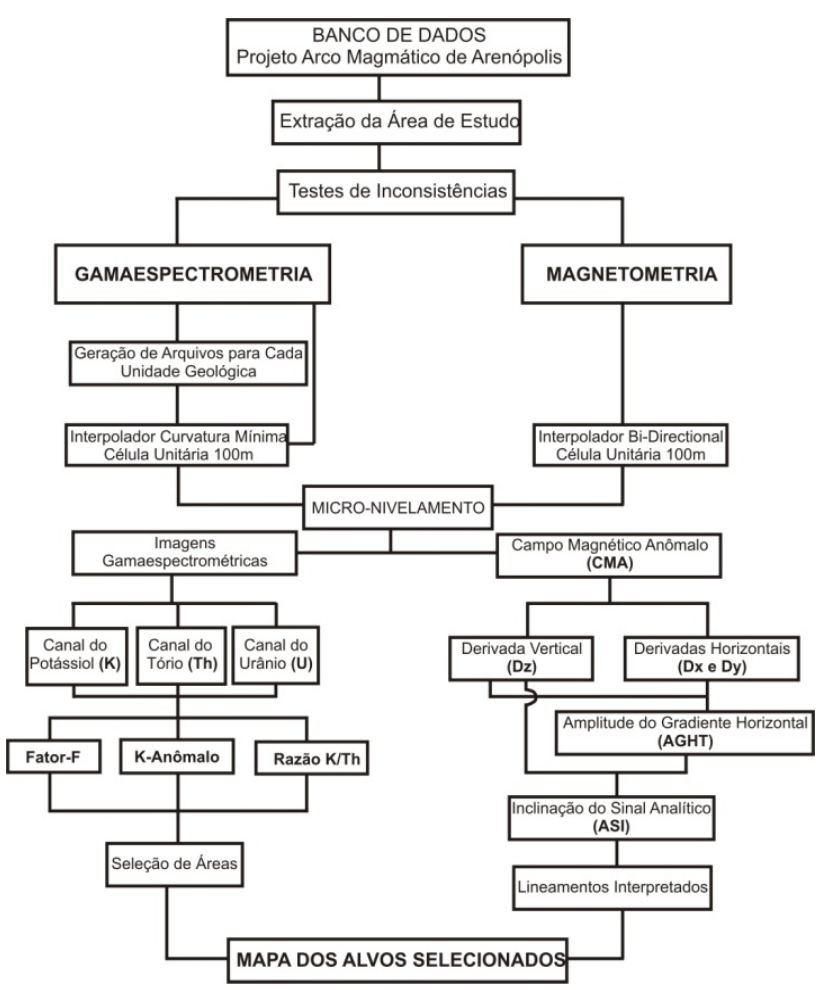

Figura 3 - Fluxograma do processamento dos dados.

\section{Resultados}

Sistemas de zonas de cisalhamento podem acumular fluidos hidrotermais portadores de metais ou controlar a distribuição destes fluidos, sendo a identificação das feições estruturais de uma região a principal utilização das imagens magnetométricas para a prospecção de mineralizações auríferas. A área de estudo engloba em sua porção leste a Zona de Cisalhamento Fazenda Nova, a qual é composta por quartzo e muscovita e não apresenta minerais magnéticos, sendo representada apenas na interpretação das feições estruturais gamaespectrométricas (Fig. 4). Os lineamentos radiométricos mostram direções principais segundo NW$\mathrm{NE}$, enquanto que as estruturas magnéticas apresentam 
direção mais freqüente EW, as quais são cortadas por estruturas maiores de direção NE e NW (Fig. 4). Os maiores gradientes magnéticos da área ocorrem associados aos corpos da Província Alcalina de Goiás e às rochas vulcânicas máficas da Seqüência de Jaupaci (Fig. 4).

A imagem classificada do canal do potássio ilustra que os granitos orogênicos estão associados aos maiores conteúdos de potássio (Fig. 5). Nesta imagem observa-se um alto valor radiométrico alinhado na direção NS na parte leste da área de estudo, o qual representa a Zona de Cisalhamento Fazenda Nova. As ocorrências de ouro estão associadas a todas as classes de conteúdo de potássio, inclusive ao backgroung (valores abaixo da média), enquanto que a Mina Bacilândia está associada a valores acima da média, mas não anômalos. Verifica-se que as áreas anômalas em potássio na imagem da razão $\mathrm{K} / \mathrm{Th}$ estão principalmente relacionadas com a unidade vulcânica félsica, enquanto que os menores valores associam-se às coberturas lateríticas e ao domínio dos ortognaisses (Fig. 6). A imagem do Fator-F destaca áreas das intrusões graníticas e também porções da unidade vulcânica, assim com a Zona de Cisalhamento Fazenda Nova (Fig. 7). A imagem do Potássio Anômalo ilustra áreas enriquecidas em potássio similares à imagem da razão Th/K (Fig. 8). Os valores anômalos estão relacionados às vulcânicas félsicas, à Zona de Cisalhamento Fazenda Nova, à porção sul do domínio dos ortognaisses e parte da intrusão alcalina. Os menores valores também são atribuídos a cobertura detrítica, mas também a partes das intrusões graníticas.

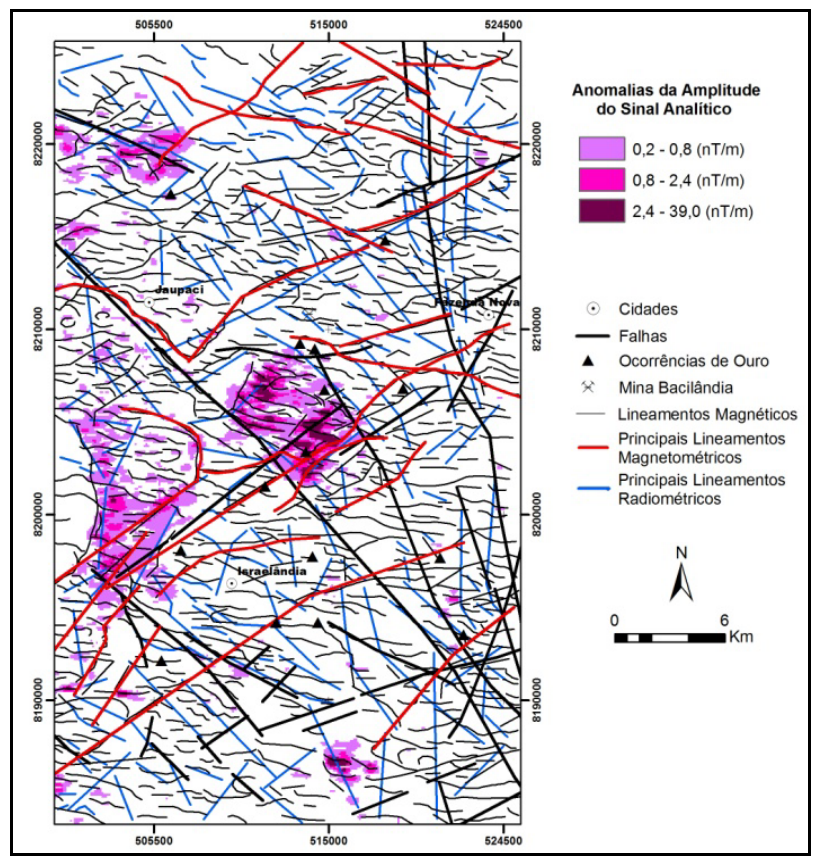

Figura 4 - Estruturas magnéticas interpretadas com os valores magnéticos anômalos.

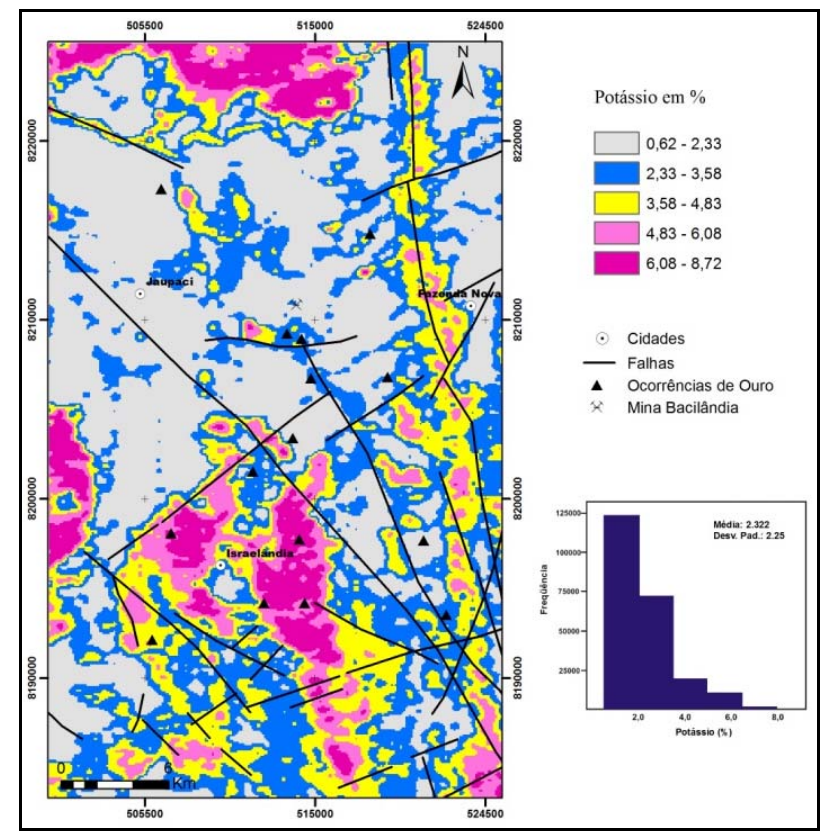

Figura 5 - Imagem do canal potássio classificado.

O gráfico de espalhamento K (\%) x Th (ppm) da área não segue uma função linear ( Fig. 9), já que envolve uma ampla variedade de litotipos. Quanto maior a dispersão dos dados, menos eficiente é a técnica do potássio anômalo. Assim, Pires (1995) sugere que a técnica seja aplicada em unidades geológicas homogêneas. Desse modo, foram criadas diferentes base de dados para cada unidade geológica a fim de obter uma melhor análise das áreas submetidas a processos de alteração hidrotermal. A Seqüência Vulcano-Sedimentar de Jaupaci apresenta duas diferentes dispersões lineares, as quais estão associadas às diferentes composições das rochas vulcânicas félsicas e ao diferente grau de alteração, enquanto que o gráfico $\mathrm{K}(\%) \times \mathrm{Th}(\mathrm{ppm})$ referente ao domínio da cobertura detrito-laterítica ilustra baixos valores de potássio para variados valores de tório (Fig. 10). A imagem do potássio anômalo com a Seqüência Jaupaci individualizada mostrou aumento na intensidade das anomalias positivas visualizadas na imagem do potássio anômalo para toda a área de estudo (Fig. 11). As principais anomalias são encontradas na parte norte $\mathrm{e}$ sul da Mina Bacilândia, na parte sul da cidade Jaupaci e nas rochas vulcânicas localizadas entre os granitos Iporá e Israelândia (parte leste e central da área) (Fig. 11). A imagem do potássio anômalo referente à cobertura laterítica mostrou que os locais com enriquecimento em potássio diferem daqueles visualizados na imagem para toda a área, sendo que os maiores valores de potássio anômalo são observados nos contatos entre as coberturas detríticas e as vulcânicas intermediárias (Fig. 11). Este contato também se apresenta como o local preferencial para áreas com enriquecimento em potássio na imagem ternária CMY com a composição dos critérios adotados: razão K/Th, Potássio Anômalo e Fator-F (Fig. 12). $\mathrm{Na}$ seleção dos alvos de áreas possíveis de representarem zonas de alteração hidrotermal, foram selecionados os centros das anomalias das áreas 
enriquecidas em potássio e desconsideradas as anomalias diretamente relacionadas à intrusão granítica e alcalina e à zona de cisalhamento (Fig. 12).

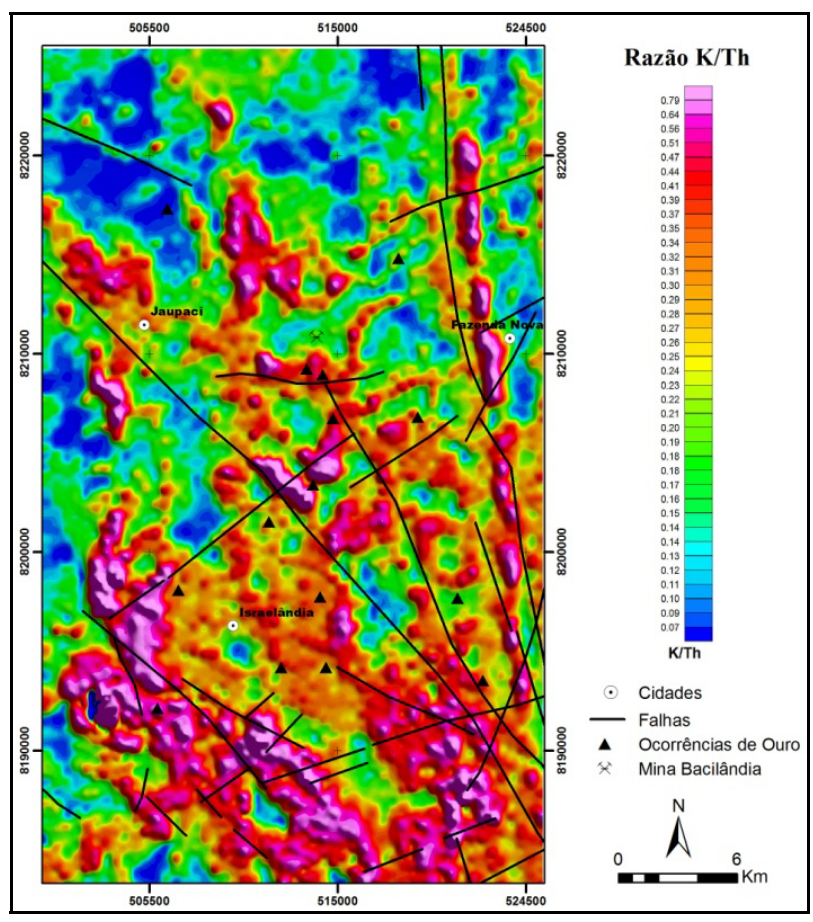

Figura 6 - Imagem da razão K/Th.

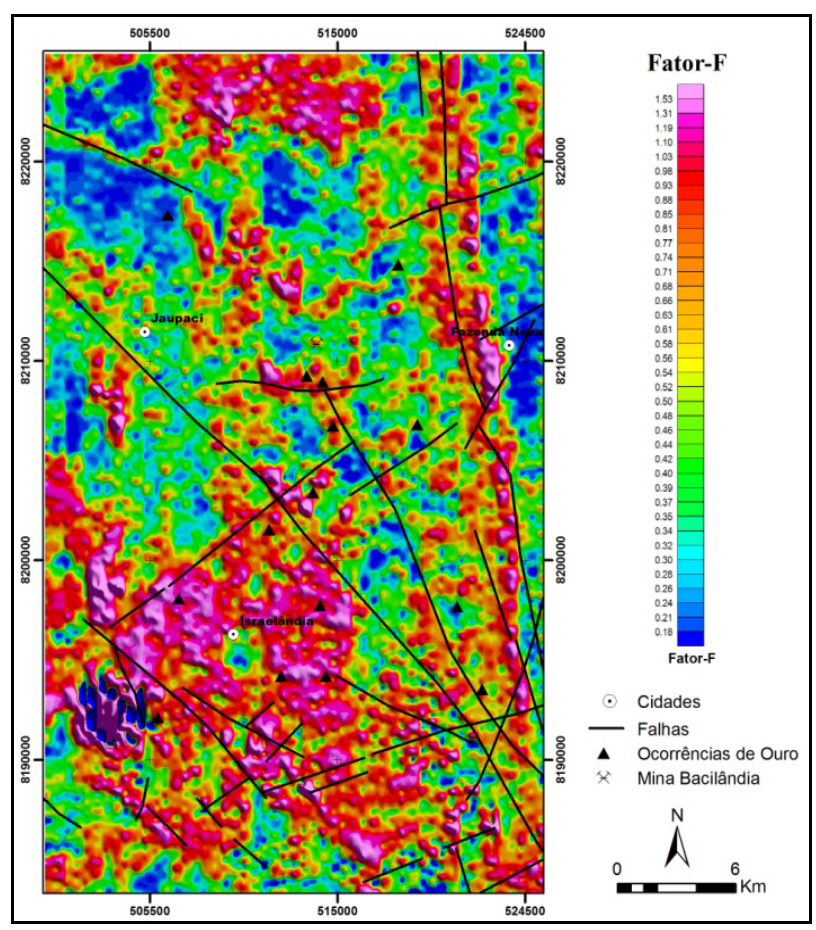

Figura 7 - Imagem do Fator-F.

\section{Discussão e Conclusões}

A imagem CMY com a integração da imagem do potássio anômalo, razão $\mathrm{K} / \mathrm{Th}$ e Fator-F ilustra áreas com alto potencial para hospedarem zonas de alteração hidrotermal, já que integra os três critérios utilizados para a identificação de áreas com valores anômalos em potássio, mostrando zonas enriquecidas em preto e locais empobrecidos em branco. Nesta imagem, as zonas enriquecidas em potássio possuem relação com o contato entre as coberturas detríticas e as rochas vulcânicas. Contudo, estas zonas também podem estar relacionadas à erosão da unidade vulcânica e a dispersão próxima à cobertura residual, já que os dados de espectrometria gama são fortemente afetados pelos processos de lixiviação.

As rochas vulcânicas máficas e félsicas entre os granitos Iporá e Israelândia, localizados na porção sudoeste da área, possuem anomalias positivas de potássio em todos os critérios assumidos para a identificação da favorabilidade de ouro associado a zonas de alteração hidrotermal. Esses alvos consistem locais propícios para a alteração devido ao aumento da temperatura e ao maior aporte de fluidos hidrotermais relacionados às intrusões graníticas. A presença de diques de basaltos, que são mais suscetíveis à alteração por fluidos hidrotermais, também favoreceu a alteração destas rochas.

As áreas selecionadas como anômalas não incluem o Depósito de Bacilândia devido à espessa cobertura laterítica na área da mina, já que a gamaespectrometria possui detecção superficial da radiação e realiza medições em até $50 \mathrm{~cm}$ no solo.

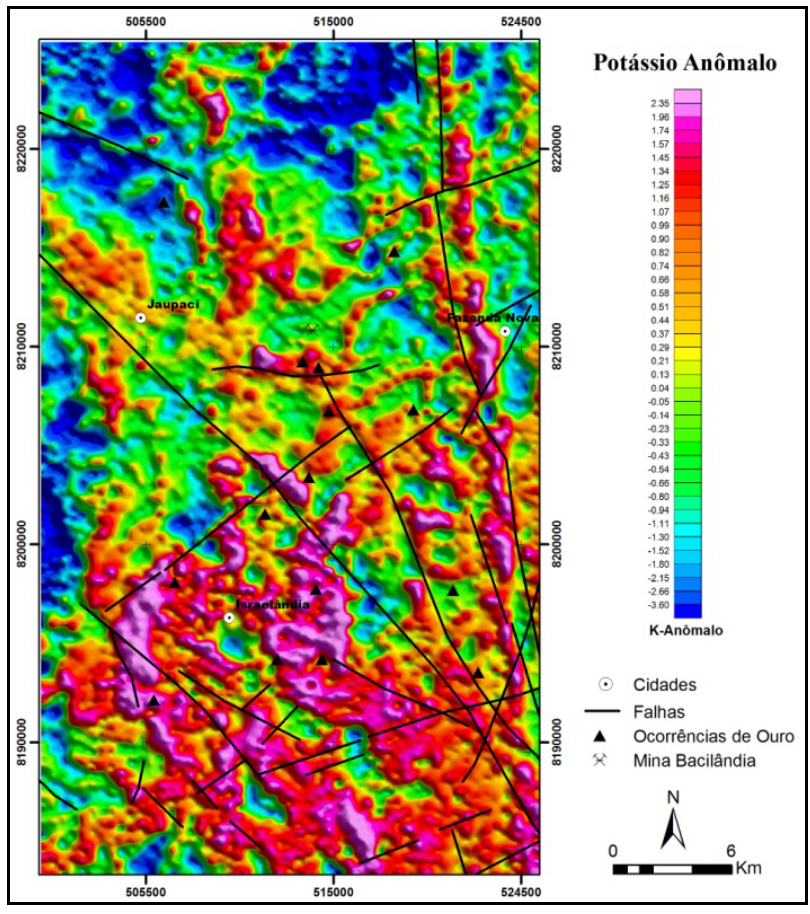

Figura 8 - Imagem do potássio anômalo para toda a área de estudo. 


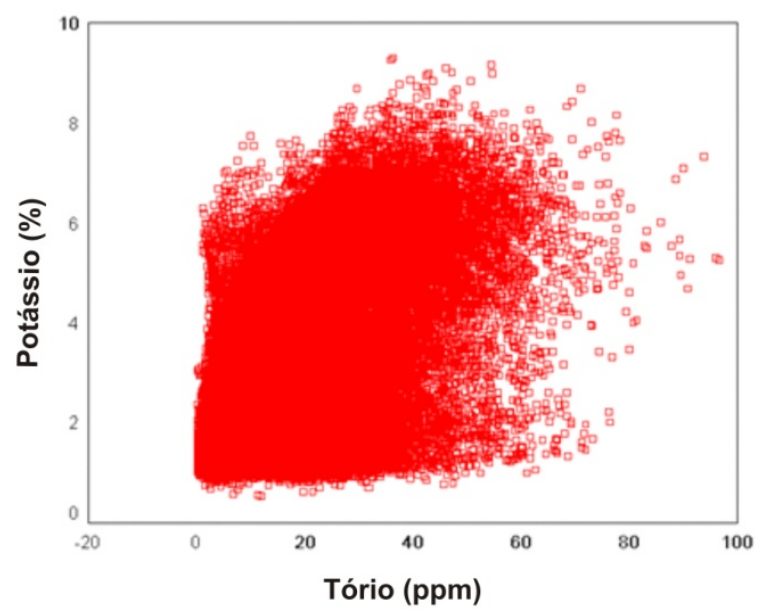

Figura 9 - Gráfico de espalhamento $K \times$ Th para toda a área de estudo.
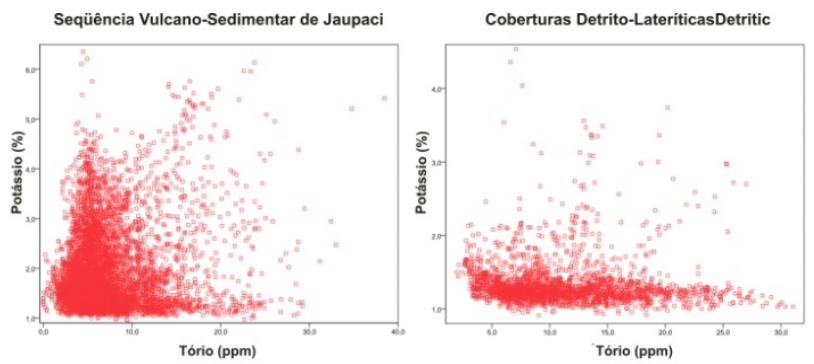

Figura 10 - Gráfico de espalhamento $K \times$ Th para a Seqüência Vulcano-Sedimentar Jaupaci e para as coberturas detrito-laterítica.

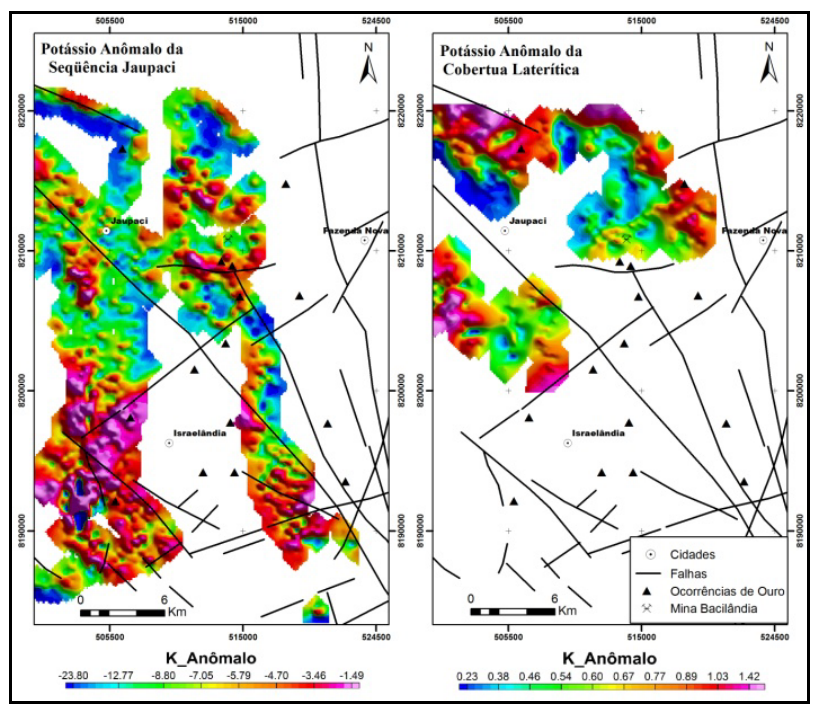

Figura 11 - Imagem do potássio anômalo para os domínios da Seqüência Jaupaci e das coberturas lateríticas.

\section{Agradecimentos}

Ao Serviço Geológico de Brasil-CPRM e à Secretaria de Indústria e Comércio-Superintendência de Geologia do Estado de Goiás pela liberação dos dados de geofísica aérea, à Yamana Gold pela disponibilização dos testemunhos de sondagem do Depósito Bacilândia e à Coordenação de Aperfeiçoamento de Pessoal de Nível Superior (CAPES) pela bolsa de estudos concedida.

\section{Referências}

Blum, M. L. B., 1999. Processamento e interpretação de dados de geofísica aérea no Brasil Central e sua aplicação à geologia regional e à prospecção mineral. Tese de Doutorado. Instituto de Geociências da Universidade de Brasília, 229p.

Efimov, A. V., 1978. Multiplikativnyj pokazatel dlja vydelenija endogennych rud pó aerogammaspektrometriceskim dannym. In: Metody rudnoj geofiziki, edited by: Naucno-proizvodstvennoje objedinenie "Geofizika" Leningrad.

Gnojek, I. \& Prichystal, A., 1985. A new zinc mineralization detected by airborne gamma-ray spectrometry in Northern Moravia, Checoslováquia. Geoexploration, 23: 491-502.

Gunn, P.J., 1998. Interpretation of Airborne Magnetic and Radiometric Surveys. AGSO, 150p.

Kuyumjian, R. M. \& Jost, H., 2009. Depósitos de ouro dos terrenos granito-greenstone de Goiás e Tocantins e de cobre e/ou ouro do Arco Magmático de Goiás: em busca de modelos geológicos para a exploração mineral. In: Simpósio Brasileiro de Metalogenia, II, Atas...Gramado.

Minty, B. R. S., 1991. Simple Micro-Levelling for Aeromagnetic Data. Exploration Geophysics, 22:591-592.

Oliveira, C. G.; Queiroz, C. L.; Pimentel, M. M. 2000. The Arenópolis-Mara Rosa Gold-Cooper Belt, Neoproterozóico Goiás Magmatic Arc. Revista Brasileira de Geociências, 30(2): 219-221.

Ostrovsky, E. Ya., 1975. Antagonism of radioactive elements in wallrock alterations fields and its use in aerogamma spectrometric prospecting. Internat. Geology Rev., 17 (4): 461-468.

Pimentel, M. M. \& Fuck, R. A., 1992. Neoproterozoic crustal accretion in central Brazil. Geology, v. 20: 375379.

Pires, A. C. B., 1995. Identificação geofísica de áreas de alteração hidrotermal, Crixás-Guarinos, Goiás. Revista Brasileira de Geociências, 25(1): 61-68.

Vasconcelos, R. M., Metelo, J. M.; Mota, C. A.; Gomes, D. R., 1994. Geofísica em levantamentos geológicos no Brasil. Rio de Janeiro. CPRM. 172p. 

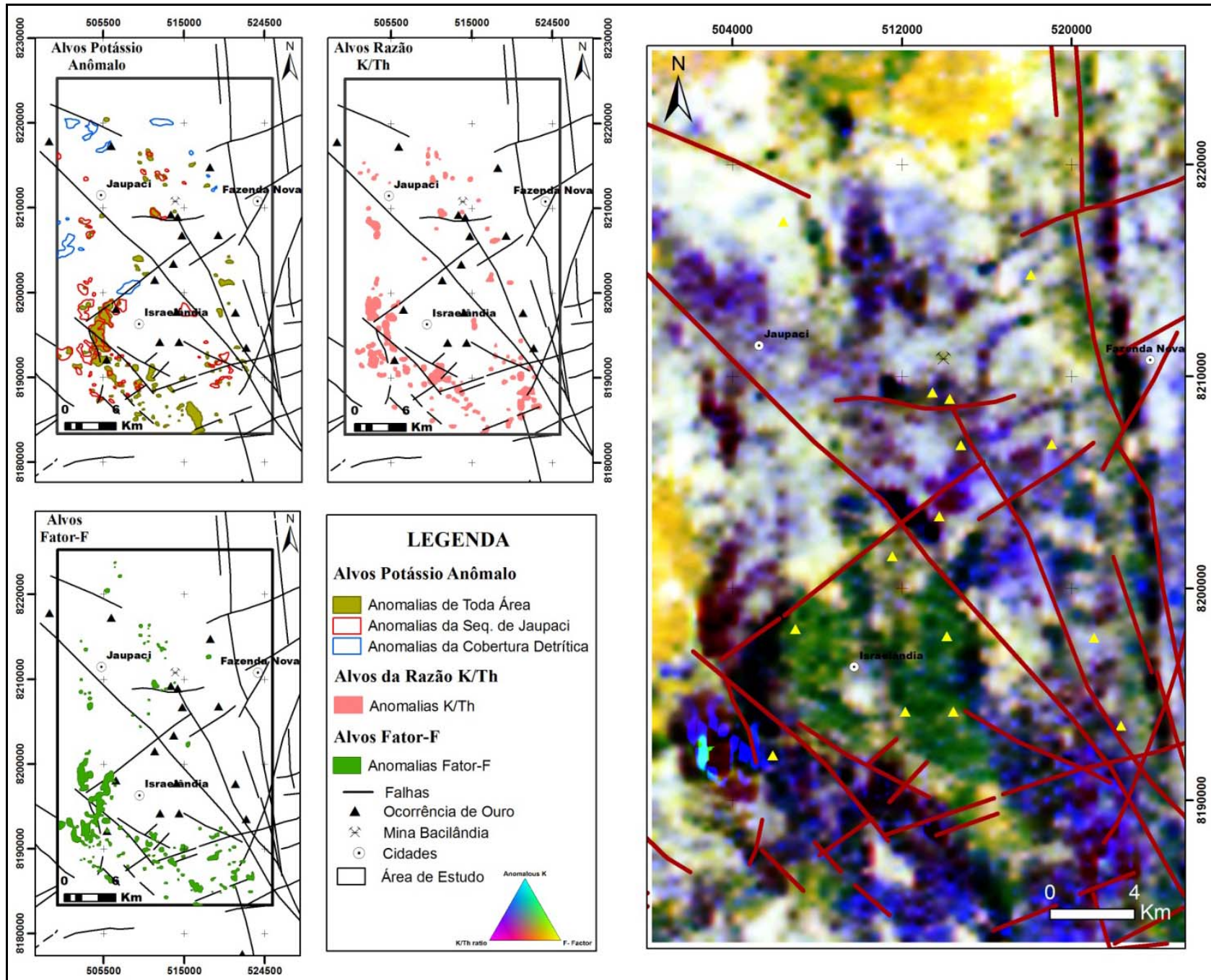

Figura 12 - Áreas prováveis de hospedarem zonas de alteração hidrotermal, a partir da identificação de enriquecimento em potássio, nas imagens potássio anômalo, razão $K / T h$ e fator- $F$, e imagem $C M Y$ com composição dos três critérios prospectivos adotados. 